\title{
Tolerance of the students at the Medical University in Białystok for different race, language and religion
}

\author{
Justyna Sarosiek ${ }^{1}{ }_{B, E}$, Katarzyna Długołędzka ${ }_{C, E}$, Katarzyna Paulina Mazur ${ }_{B, G}{ }^{1}$ Katarzyna \\ Van Damme-Ostapowicz ${ }_{\mathrm{A}, \mathrm{D}, \mathrm{E}, \mathrm{E}}$ Elżbieta Krajewska-Kułak ${ }_{\mathrm{B}, \mathrm{F}}$
}

\author{
${ }^{1}$ Student's Scientific Circle “Tropik” at the Department of Integrated Medical Care, Medical \\ University in Białystok \\ ${ }^{2}$ Department of Integrated Medical Care at the Medical University of Białystok
}

The statute-based study no. 113-10540 executed at the Department of Health Sciences of the Medical University in Białystok

\begin{abstract}
Studies on the attitude of youth towards cultural, ethnic and religious minorities are currently necessary and important for several reasons. The diagnosis of those attitudes is important both for the prediction of development of intercultural dialogue and cooperation, and foreseeing the threats of conflicts and animosities, as well as the design of any necessary educational actions. The importance of those issues may be discussed from various perspectives: global, European, Polish, regional and local.
\end{abstract}

\section{Objective}

The objective of the study was to assess the tolerance of the students at the Medical University in Białystok for different race, language and religion.

Methods

The study was based on a custom survey questionnaire, in a group of 198 students at the Medical University in Białystok.

\section{Results:}

The majority of subjects (96\%) declared a high or moderate level of overall tolerance.

$53 \%$ of subjects expressed their strong support of the idea of acceptance of students from other countries to their school. "Age" is a factor that influences the diversity of the examined students" assessment of the relationships "between foreign students and Polish students," where $\mathrm{p}=0.0032 * *$. "The field of study" is a factor that influences the differentiation of responses related to the "influence of religion on socializing".

\section{Conclusions:}

1. The majority of subjects declared a high or moderate level of overall tolerance.

2. More than half of the subjects express their strong support of the idea of opening their school to foreign students.

3. There is a statistically significant relation between age, field of study, year of study and the attitudes of students towards different race, language and religion.

4. Relatively older people are more sceptical to a relationship with a person of a different race; similarly, students of older years are less optimistic about how foreign students would feel at the University.

Keywords: students, tolerance, race

\section{Introduction}

There are approximately 7000 different ethnic and national groups in the world. Most tensions between people stem from prejudice and intolerance. Since its very beginning Poland may be considered a multicultural and multi-religious country. It is estimated [op. cit. 1] that there are 253 thousand members of national minorities in Poland, and there are 21 million Polish people living outside Poland, including 10,600,000 in the US, 1,800,000 in Brazil, over 1,000,000 in France, 900,000 in Canada, 500,000 in the UK, 450,000 in Argentina, 200,000 in Australia, 100,000 in Kazakhstan and the same number in Sweden, 89,000 in Ireland 
(up to a quarter of million), 75,000 in Latvia, 70,000 in Belgium, 60, in the Netherlands, 55,000 in Austria, 50,000 in Greece, 45,000 in Spain, 35,000 in South Africa, 20,000 in Denmark and Switzerland, 10,000 each in Mexico, Moldavia and Romania.

The literature [2] also indicates that there are between 3,000 and 7,000 various ethnic and national groups in the world, and the majority of tensions between people, populations and nations stems from prejudice and intolerance. The fact is emphasized [2] that in newly-formed countries or regions, some ethnic groups are marginalized, as it is in the case of Serbs in Croatia, Bosnia and Herzegovina, Albanians in Kosovo, Armenians in Nagorno-Karabakh, and Azeri in Nakhichevan. According to Węgrzecki [3], the limit of tolerance of attitudes, opinions and beliefs is defined by biological, economic and spiritual threats determined by human needs (love thy neighbor), and also by respect to another man and one's own morality. Hence, drawing the line between tolerance and intolerance is very difficult [3].

Hammer [4] believes that "intolerance, as a set of prejudice, is a negative and arbitrary attitude based on incomplete or false data, excessively simplified, often illogical, rigid and resistant to any changes." It is the lack of acceptance of being 'different' the behavior, opinions, outlook and appearance of foreigners, as well as the spheres of worldview and ideals of another human being. It is a desire to destroy or alter the difference and foreignness of the unknown [4]. In Chlewiński's opinion [5], tolerance is "a desirable feature which every human should be taught about and prepared for in early childhood, by the demonstration of unconditional love to a child and the use of mild and warm educational methods." The author is convinced that a positive example, coherence between words and deeds and consequence of actions and education are of immense importance. "Independent thinking is an ally for the development of a tolerant attitude in oneself and in other people. That is the way intolerance may be prevented. It is also the principal way to overcome prejudice that has already partially deformed our perception of the world." [5]

Prejudice and stereotypes, expressed by various attitudes, and usually based on lines of ethnic and sexual divisions, may be observed in very young children. [1] Therefore, much depends on how an individual was raised during his/her childhood, starting from attitudes created by parents, through teachers, to shaping by media and society [1]. According to Strzeszewski [6], the emotional attitude of Polish people to foreigners is currently gathering more and more importance, because contact between people of various nations is no longer exceptional, but is becoming an element of everyday life. Historically shaped stereotypes (both positive and negative), as well as the image shaped by the media create the climate of those contacts. At the same time, experience and observations resulting from direct contact with people of other nationalities modify the old stereotypes. [6] The phenomena of stereotyping and xenophobia have become important lately, considering the fact that immigrants, refugees and migrating workers are perceived as a threat in the labour market, conditions of life thus far and cultural identity.

\section{Material and methods}

The study was performed on a group of 198 students at the Medical University in Białystok, Podlaskie voivodship, following the approval no. R-I002/339/2011 obtained from the Bioethical Committee of the Medical University in Białystok.

The method of a diagnostic survey was used for that purpose, using the custom-developed survey questionnaire. The introduction of the questionnaire contained information on: the purpose of the study, voluntary character and anonymity of responses, the right to withdraw from the study at any point and the way of filling in the questionnaire.

The research tool was the custom-made survey questionnaire.

The results which were obtained will allow an objective assessment of the subject, and may become the basis for a future national study in all Polish Medical Universities.

\section{Data acquisition}

The survey and data analysis took a year. The questionnaire was completed in Polish. The Project Manager was present when the questionnaire was being filled in. Before the start of the study, its objectives and methods were explained to each of the respondents. Filling in a single questionnaire took from 20 to 30 minutes.

\section{Statistical analysis}

The data analysis was completed involving the quantitative and relative distribution of answers in the group of females and males. Selected statistical tests were additionally applied. The statistical significance of a difference between responses in relation to gender was assessed using the chi-squared test. In all included analyses regarding the effect of gender on the tolerance level, the $\mathrm{p}$ value $>0.05$ was obtained. Therefore the effect of that factor on the opinions of the surveyed students cannot be claimed. In one case the result was close to statistical significance - that was the case of the effect of gender on the question of the importance of origin in socializing.

As the factors of age and the year of study are of an ordinal character (response variants may be ordered, which means that it makes sense to state that the younger the person was, the lower the year of his/ her studies was) and responses to questions 6-17 were of a similar character, so it was possible to apply the Spearman rank correlation coefficient to the analysis. Thus 
a collective table was constructed, containing information regarding over twenty of analyzed associations. The approach involving the correlation analysis was an interesting one because it allowed the determination of associations that were logically directed - for example, that the level of tolerance decreased with age.

\section{Results}

\section{Participants}

The survey questionnaire was distributed among 198 students of medical fields at the Medical University in the Podlaskie voivodship. The first part of the paper presented the general characteristics of the study population. Women constituted the vast majority of the participants of the survey - approximately $4 / 5$ of the study group.

The most numerous group of respondents were students of nursing (over $1 / 3$ of the population), every fourth surveyed was a student of physiotherapy, and every tenth - a student of the medical faculty (Table 1). or less) by every seventh respondent. Others could see no threat for themselves.

More than half of the surveyed students strongly supported the idea of opening the University for foreign students.

In all, over $85 \%$ of subjects believed that foreigners could feel at ease or quite at ease in their school, and as few as one in ten thought otherwise.

According to the surveyed students, Polish students are friendly to foreigners, although every third believed that the attitude was neutral (terms "negative" or "hostile" were sporadic).

The structure of responses to the question regarding relations between foreign and Polish students is very similar

Over $3 / 4$ of respondents declared their readiness to help a foreigner threatened by direct violence. The problem of the religion of peers seemed unimportant for the majority of students, although it is notable that Islam is the least popular religion.

Students did not indicate those nationalities that, in their opinion, were the least tolerated in the Uni-

Table 1. Respondents' field of study

\begin{tabular}{|c|c|c|}
\hline Field of study & Number & Ratio \\
\hline Nursing & 77 & $38.9 \%$ \\
\hline Physiotherapy & 51 & $25.8 \%$ \\
\hline Medicine & 26 & $13.1 \%$ \\
\hline Dietetics & 23 & $11.6 \%$ \\
\hline Medical Rescue & 16 & $8.1 \%$ \\
\hline Electro-radiology & 4 & $2.0 \%$ \\
\hline No response & 1 & $0.5 \%$ \\
\hline
\end{tabular}

All surveyed students declared Polish nationality.

\section{Assessment of students' tolerance level}

Only a minor percentage of the surveyed students declared themselves as intolerant. The majority declared a high or moderate level of overall tolerance. In the case of the religious tolerance, over $80 \%$ of respondents declared that the religion of their peers was not a differentiating criterion for them.

Also the origin of peers had only a slight effect on the attitude of students towards them. Slightly more of them, every tenth, took that aspect into consideration while socializing.

Responses to the question regarding relationships with a person of a different faith were a bit more complex. In this case, every fourth person would not be fully sure about a relationship, and more or less every eleventh expressed a strict rejection of that idea.

The neighbourhood of a foreigner is not a negative, stressful or fear-arousing situation for modern students. Studies in the same school are opposed (more versity. Sporadic examples of Arab countries, Romania and Russia were mentioned.

II Effect of selected social and demographic factors on the attitude of students towards different race, language and religion

\subsection{Gender and students' attitude towards different race, language and religion}

In no case did gender determine the level of students' tolerance for people of other race and religion. In the case of the effect of gender on the importance of origin in socializing, the result was close to statistical significance (Table 2). 
Table 2. The effect of religion on socializing, according to opinions of the surveyed students

\begin{tabular}{|c|c|c|c|}
\hline \multirow{2}{*}{$\begin{array}{c}\text { Effect of religion on } \\
\text { socializing }\end{array}$} & female & male & \multirow{2}{*}{ Total } \\
\cline { 2 - 4 } & $4(2.4 \% \downarrow)$ & $2(5.9 \% \downarrow)$ & 6 \\
\hline Strong positive & $21(12.8 \% \downarrow)$ & $4(11.8 \% \downarrow)$ & 25 \\
\hline Rather positive & $64(39.0 \% \downarrow)$ & $7(20.6 \% \downarrow)$ & 71 \\
\hline Rather negative & $75(45.7 \% \downarrow)$ & $21(61.8 \% \downarrow)$ & 96 \\
\hline Strong negative & 164 & 34 & 198 \\
\hline Total & & & $\mathbf{2}$ \\
\hline
\end{tabular}

\subsection{Age and students' attitude towards different race, language and religion}

For the simplicity of analysis, the surveyed students were divided into three age groups. Observing the indications given by respondents, no clear age-associated differences in responses to the study-related questions could be noted for the majority of issues which were discussed. Contingency tables present the results of the chi-squared independence test.

The only statistically significant association concerned the relation between age and the assessment of attitude of foreign students to Polish ones. In the "middle" age group the number of people who found that relation "neutral" was the highest. The other two groups indicated that the relation is friendly (Table 3 ).

\subsection{Field of study and students' attitudes towards dif- ferent race, language and religion}

First the fields of studies were grouped and then an analysis was performed to check if the field of study affected student's opinions.

The study demonstrated that the field of study is the factor with the strongest effect on students' tolerance. Statistically significant associations were drawn on graphs.

There is a statistically significant relation between the field of study and the respondents' responses on the topic of the effect of religion on socializing (Table 4).

Table 3. The effect of age on the assessment of the relation between foreign and Polish students

\begin{tabular}{|c|c|c|c|c|}
\hline \multirow{2}{*}{$\begin{array}{l}\text { The relation of foreign } \\
\text { to Polish students }\end{array}$} & \multicolumn{3}{|c|}{ Age $\left(p=0.0032^{\star \star}\right)$} & \multirow[t]{2}{*}{ Total } \\
\hline & Up to 22 years & 23-24 years & over 25 years & \\
\hline Very friendly & $11(18.3 \% \downarrow)$ & $8(9.4 \% \downarrow)$ & $7(13.5 \% \longleftarrow)$ & 26 \\
\hline Friendly & $32(53.3 \% \underline{\downarrow})$ & $32(37.6 \% \underline{\downarrow})$ & $35(67.3 \% \underline{\downarrow})$ & 99 \\
\hline Neutral & $15(25.0 \% \downarrow)$ & $41(48.2 \% \underline{\downarrow})$ & $9(17.3 \% \underline{ }-)$ & 65 \\
\hline Negative & $2(3.3 \% \downarrow)$ & $4(4.7 \% \downarrow)$ & $1(1.9 \% \downarrow)$ & 7 \\
\hline Total & 60 & 85 & 52 & 197 \\
\hline
\end{tabular}

Table 4. The effect of the field of study on responses to the question regarding the effect of religion on socializing

\begin{tabular}{|c|c|c|c|c|}
\hline \multirow{2}{*}{$\begin{array}{c}\text { Effect of religion on } \\
\text { socializing }\end{array}$} & \multicolumn{3}{|c|}{ Field of study $\left(\mathbf{p}=\mathbf{0 . 0 2 9 8 ^ { * } )}\right.$} & \multirow{2}{*}{ Total } \\
\cline { 2 - 5 } & nursing & Other medical & Medicine & 6 \\
\hline Strong positive & $2(2.6 \% \downarrow)$ & $4(4.2 \% \downarrow)$ & $0(0.0 \% \downarrow)$ & 25 \\
\hline Rather positive & $3(3.9 \% \downarrow)$ & $19(20.0 \% \downarrow)$ & $3(11.5 \% \downarrow)$ & 71 \\
\hline Rather negative & $35(45.5 \% \downarrow)$ & $26(27.4 \% \downarrow)$ & $10(38.5 \% \downarrow)$ & 96 \\
\hline Strong negative & $37(48.1 \% \downarrow)$ & $46(48.4 \% \downarrow)$ & $13(50.0 \% \downarrow)$ & 198 \\
\hline Total & 77 & 95 & 26 & 6 \\
\hline
\end{tabular}

There is a statistically significant relation between the field of study and the respondents' responses to the questions regarding the effect of origin on socializing (Table 5).
There is a statistically significant relation between the field of study and responses regarding studying with a student belonging to a different race (Table 6). 
Table 5. The effect of the field of study on responses regarding the effect of origin on socializing

\begin{tabular}{|c|c|c|c|c|}
\hline \multirow{2}{*}{$\begin{array}{c}\text { Effect of origin on } \\
\text { socializing }\end{array}$} & \multicolumn{3}{|c|}{ Field of study $\left(\mathbf{p}=\mathbf{0 . 0 0 3 4 ^ { * * } )}\right.$} & \multirow{2}{*}{ Total } \\
\cline { 2 - 5 } & Nursing & Other medical & Medicine & 4 \\
\hline Strong positive & $0(0.0 \% \downarrow)$ & $4(4.2 \% \downarrow)$ & $0(0.0 \% \downarrow)$ & 22 \\
\hline Rather positive & $1(1.3 \% \downarrow)$ & $15(15.8 \% \downarrow)$ & $6(23.1 \% \downarrow)$ & 82 \\
\hline Rather negative & $38(50.0 \% \downarrow)$ & $37(38.9 \% \downarrow)$ & $7(26.9 \% \downarrow)$ & 89 \\
\hline Strong negative & $37(48.7 \% \downarrow)$ & $39(41.1 \% \downarrow)$ & $13(50.0 \% \downarrow)$ & 197 \\
\hline Total & 76 & 95 & 26 & \\
\hline
\end{tabular}

There is a statistically significant relation between the field of study and responses regarding foreigners feeling generally at ease at school, according to the respondent's opinions (Table 7).

Table 6. The effect of the field of study on responses regarding studying with a person belonging to a different race

\begin{tabular}{|c|c|c|c|c|}
\hline \multirow{2}{*}{$\begin{array}{c}\text { Opposition against } \\
\text { studying with people } \\
\text { of a different race }\end{array}$} & \multicolumn{3}{|c|}{ Field of study $(\mathbf{p}=\mathbf{0 . 0 2 0 9 *}$} & \multirow{2}{*}{ Total } \\
\cline { 2 - 5 } & Nursing & Other medical & Medicine & \\
\hline Strong positive & $5(6.5 \% \downarrow)$ & $12(12.6 \% \downarrow)$ & $0(0.0 \% \downarrow)$ & 17 \\
\hline Rather positive & $2(2.6 \% \downarrow)$ & $12(12.6 \% \downarrow)$ & $0(0.0 \% \downarrow)$ & 14 \\
\hline Rather negative & $9(11.7 \% \downarrow)$ & $10(10.5 \% \downarrow)$ & $3(11.5 \% \downarrow)$ & 22 \\
\hline Strong negative & $61(79.2 \% \downarrow)$ & $61(64.2 \% \downarrow)$ & $23(88.5 \% \downarrow)$ & 145 \\
\hline Total & 77 & 95 & 26 & 198 \\
\hline
\end{tabular}

Table 7. The effect of the field of study on responses regarding foreigners feeling generally at ease at the school, in the respondents' opinion

\begin{tabular}{|l|l|l|l|l|}
\hline \multirow{2}{*}{$\begin{array}{l}\text { Do foreign students } \\
\text { feel at ease at school? }\end{array}$} & \multicolumn{2}{|l|}{ Field of study $(\mathbf{p}=\mathbf{0 . 0 0 0 7})$} & Total \\
\cline { 2 - 4 } & Nursing & Other medical & Medicine & \\
\hline Strong positive answer & $9(11.7 \% \downarrow)$ & $22(23.7 \% \downarrow)$ & $8(30.8 \% \downarrow)$ & 39 \\
\hline Rather positive & $62(80.5 \% \downarrow)$ & $61(65.6 \% \downarrow)$ & $9(34.6 \% \downarrow)$ & 132 \\
\hline Rather negative & $6(7.8 \% \downarrow)$ & $9(9.7 \% \downarrow)$ & $8(30.8 \% \downarrow)$ & 23 \\
\hline Strong negative answer & $0(0.0 \% \downarrow)$ & $1(1.1 \% \downarrow)$ & $1(3.8 \% \downarrow)$ & 2 \\
\hline Total & 77 & 93 & 26 & 196 \\
\hline
\end{tabular}

There is a statistically significant relation between the field of study and responses regarding the attitude of foreign students towards Polish students (Table 9).
There is a statistically significant relation between the field of study and responses regarding the reaction to violence towards a foreign student, in the opinion of Polish students (Table 10).

Table 8. The effect of the field of studies on responses regarding the attitude of Polish students towards their foreign colleagues

\begin{tabular}{|c|c|c|c|c|}
\hline \multirow{2}{*}{$\begin{array}{c}\text { The attitude of Polish } \\
\text { students towards fore- } \\
\text { ign students }\end{array}$} & Nursing & Other medical & Medicine & Total \\
\cline { 2 - 5 } & $7(9.1 \% \downarrow)$ & $14(15.1 \% \downarrow)$ & $2(7.7 \% \downarrow)$ & 23 \\
\hline Very friendly & $48(62.3 \% \downarrow)$ & $49(52.7 \% \downarrow)$ & $7(26.9 \% \downarrow)$ & 104 \\
\hline Friendly & $20(26.0 \% \downarrow)$ & $22(23.7 \% \downarrow)$ & $15(57.7 \% \downarrow)$ & 57 \\
\hline Neutral & $2(2.6 \% \downarrow)$ & $6(6.5 \% \downarrow)$ & $1(3.8 \% \downarrow)$ & 9 \\
\hline Negative & $0(0.0 \% \downarrow)$ & $2(2.2 \% \downarrow)$ & $1(3.8 \% \downarrow)$ & 3 \\
\hline Hostile & 77 & 93 & 26 & 196 \\
\hline Total & & & & \\
\hline
\end{tabular}


Table 9. Effect of the field of study on responses regarding the attitude of foreign students towards Polish students

\begin{tabular}{|c|c|c|c|c|}
\hline \multirow{2}{*}{$\begin{array}{c}\text { The attitude of foreign } \\
\text { students towards Po- } \\
\text { lish students }\end{array}$} & Nursing & Other medical & Medicine & \multirow{2}{*}{ Total } \\
\cline { 2 - 5 } & $7(9.1 \% \downarrow)$ & $18(19.1 \% \downarrow)$ & $1(3.8 \% \downarrow)$ & 26 \\
\hline Very friendly & $46(59.7 \% \downarrow)$ & $48(51.1 \% \downarrow)$ & $5(19.2 \% \downarrow)$ & 99 \\
\hline Friendly & $19(24.7 \% \downarrow)$ & $28(29.8 \% \downarrow)$ & $18(69.2 \% \downarrow)$ & 65 \\
\hline Neutral & $5(6.5 \% \downarrow)$ & $0(0.0 \% \downarrow)$ & $2(7.7 \% \downarrow)$ & 7 \\
\hline Negative & 77 & 94 & 26 & 197 \\
\hline Hostile & & & \\
\hline
\end{tabular}

Table 10. Effect of the field of study on responses regarding the reaction to violence towards a foreign student, in the opinion of Polish students

\begin{tabular}{|c|c|c|c|c|}
\hline \multirow{2}{*}{$\begin{array}{c}\text { Reaction to violence } \\
\text { towards a foreign stu- } \\
\text { dent }\end{array}$} & \multicolumn{3}{|c|}{ Field of study $\left(\mathbf{p}=\mathbf{0 . 0 2 1 6 ^ { \star }}\right)$} & \multirow{2}{*}{ Total } \\
\cline { 2 - 5 } & Nursing & Other medical & Medicine & 62 \\
\hline Strongly yes & $25(32.5 \% \downarrow)$ & $25(26.3 \% \downarrow)$ & $12(46.2 \% \downarrow)$ & 94 \\
\hline Rather yes & $44(57.1 \% \downarrow)$ & $44(46.3 \% \downarrow)$ & $6(23.1 \% \downarrow)$ & 12 \\
\hline Rather no & $3(3.9 \% \downarrow)$ & $8(8.4 \% \downarrow)$ & $1(3.8 \% \downarrow)$ & 2 \\
\hline Strongly no & $0(0.0 \% \downarrow)$ & $2(2.1 \% \downarrow)$ & $0(0.0 \% \downarrow)$ & 28 \\
\hline Don't know & $5(6.5 \% \downarrow)$ & $16(16.8 \% \downarrow)$ & $7(26.9 \% \downarrow)$ & 198 \\
\hline Total & 77 & 95 & 26 & \\
\hline
\end{tabular}

\subsection{Year of studies and students' attitudes towards dif- ferent race, language and religion}

It seems that the year of studies (just like age) had no greater effect on students' responses. Respondents from all years were characterized by a high level of tolerance for foreigners and people of different religion.
There is a statistically significant relation between the year of studies and responses regarding the attitude of foreign students towards Polish students (Table 11).

Table 11. Effect of the year of studies on responses regarding the attitude of foreign students towards Polish students

\begin{tabular}{|c|c|c|c|c|c|}
\hline \multirow{2}{*}{$\begin{array}{c}\text { Attitude of foreign } \\
\text { students towards } \\
\text { Polish students }\end{array}$} & I/II & III & IV & \multirow{2}{*}{ Total } \\
\hline Very friendly & $6(9.4 \% \downarrow)$ & $7(28.0 \% \downarrow)$ & $6(12.5 \% \downarrow)$ & $7(11.9 \% \downarrow)$ & \\
\hline Friendly & $37(57.8 \% \downarrow)$ & $14(56.0 \% \downarrow)$ & $28(58.3 \% \downarrow)$ & $20(33.9 \% \downarrow)$ & 26 \\
\hline Neutral & $19(29.7 \% \downarrow)$ & $3(12.0 \% \downarrow)$ & $12(25.0 \% \downarrow)$ & $30(50.8 \% \downarrow)$ & 69 \\
\hline Negative & $2(3.1 \% \downarrow)$ & $1(4.0 \% \downarrow)$ & $2(4.2 \% \downarrow)$ & $2(3.4 \% \downarrow)$ & 7 \\
\hline Total & 64 & 25 & 48 & 59 & 196 \\
\hline
\end{tabular}

\subsection{Collective listing of factors, including age and year of studies, and students' attitudes towards different race, language and religion}

As the factors of age and the year of study were of an ordinal character (response variants might be ordered, which means that it makes sense to state that the younger the person is, the lower the year of his/ her studies) and responses to questions 6-17 were of a similar character, so it was possible to apply the Spearman rank correlation coefficient to the analysis. Thus we constructed a collective table containing information on over twenty analyzed relations. The approach using the correlation analysis is interesting because it allows the determination of relations that are logically directed e.g. the level of tolerance decreases with age.

The analysis of correlation provides information that the age and year of studies logically determine none of the issues mentioned in the questionnaire.

The only statistically significant relations, although weak ones $\left(\mathrm{p}=0.14^{\star}\right)$, are associated with the effect of age on the opinion about a relationship with a 
person of different race, and the year of studies on the opinion of the general feeling of ease of foreign students at school, with $\mathrm{p}=0.18^{\star *}$.

Relatively older people are more sceptical to a relationship with a person of a different race. Similarly, students of senior years are less optimistic about the feeling of ease of foreign students at school ${ }^{1}$.

\section{Discussion}

Each year Poland increasingly becomes a country of immigration. It is true that the percentage of immigrants is still low - 85,000 immigrants corresponds to approx. $0.2 \%$ of the population, whereas in the "old" EU Member States the percentage ranges between $4 \%$ and $10 \%$. However, considering the economic development and increasing emigration from Poland to EU States, it may be expected that the ratio will gradually increase, both as a result of a demand for workforce, and the generally increased migration [7].

In this study students declared a rather high level of tolerance. Kułak et al. states that only $12 \%$ students of medical schools are tolerant [8].

In their other study, Kułak et al. states that $12 \%$ of respondents found Polish people tolerant, and $37.4 \%$ believed that the level of tolerance was increasing among Polish people. Only $8 \%$ of students agreed, and $36 \%$ disagreed that it is good to have people of various nationalities in a single country [9].

In this study a high ratio of students (80\%) declared that religion has no effect on socializing. As a rule $(84 \%)$ respondents declared that every religion was equally good, and was no differentiating factor. Simple results were obtained by Kułak et al. [9].

This study demonstrated that Polish students are very open and friendly, and as many as $80 \%$ of them believed that foreigners felt at ease at school. Kułak is of the same opinion, indicating that $81 \%$ of subjects saw no signs of intolerance at school, and only $2.3 \%$ could indicate some particular examples of negative or hostile behavior towards a foreigner [8].

In the question about the attitude towards foreigners, over half of the respondents (54\%) have nothing against a foreign neighbor. However, Krajewska-Kułak et al. are of a different opinion [10]. In their studies the authors stated that a significant ratio of students (60\%) would not like to have an immigrant or member of a national minority as a neighbor [10].

In Strzeszewski's study [6], regarding the sympathy and antipathy of Polish people towards other nations, Poles were characterized as a tolerant nation. Polish people welcome Italians and French warmly. More than half declared an antipathy towards Russians, Romanians and Arabs. [6] In this study students did not indicate who, in their opinion, were the least tolerated nationalities. Sporadically, Arab countries, Romania or Russia were mentioned.

In view of the results which were obtained in the study, it appears that the increase in tolerant attitudes could be achieved with the effort of education, because only people who are aware of themselves are able to respect other cultures. The primary purpose of education should be the development of mutual knowledge and the understanding of diversity, the development of positive cross-references, a search for common cultural roots, with simultaneous rooting in the "private homeland." Intercultural education has the difficult task of shaping the need of "exploration of borderlines," exposure of the Polish tradition of pluralism, care for the common cultural heritage, the perception of "otherness" as interesting, stimulating and motivating for cooperation. Our culture, being part of a community of human culture, may develop and improve only in constant relationship with others. The educational system should, therefore, be based on a variety of values from other cultures, defying purity and cultural isolation. [11]

\section{Conclusions}

1. Majority of subjects declared high or medium level general tolerance.

2. More than half of the surveyed students strongly support the idea of studying with foreign students.

3. There is a statistically significant relation between age, field of study, year of studies and students' attitudes towards different race, language and religion.

4. Relatively older people are more sceptical about a relationship with a person belonging to a different race. Similarly, senior students are less optimistic about foreign students' feeling at ease at school.

\section{POSTULATE}

1.The introduction of training related to the topic of multi-cultural approach for students seems necessary and justified.

Authors declare no conflict of interest that could affect the objectivity and reliability of the paper "Tolerance of the students at the Medical University in Białystok for different race, language and religion."

\section{References:}

1. Bodakowski J. Ethnic and National Minorities in Poland. retrieved 12.05.2011 from http://www.bibula. $\operatorname{com} / ? \mathrm{p}=14424$.

\footnotetext{
${ }^{1}$ As response variants were coded in the following way: 1 - strongly yes, $\ldots, 4$ - strongly no (according to the order in the questionnaire). A positive correlation coefficient means a tendency for higher codes - which means negative answers.
} 
2. Ambrosewicz-Jakocobs J. Tolerance - How to Teach Yourself and Others. Leyko, Kraków 2004, p. 42-47.

3. Węgrzecki A. Tolerance as a Personal Value. In: Olbrycht K. ed., Axiological Education. Vol. 3. On Tolerance. Katowice; Uniwersytet Śląski: 1995, p.17.

4. Hammer H. The Demon of Intolerance. Warszawa; WsiP: 1994, p. 49

5. Chlewiński Z. Stereotypes: Structure, Functions, Genesis. Interdisciplinary Analysis. In: Stereotypes and Prejudices. Warszawa; Instytut Psychologii PAN: 1992, p. 309.

6. Strzeszewski M. Attitude of Poles to Other Nations. http://www.bezuprzedzen.org/doc/

06Stosunek_Polakow_do_innych_narodow_2001_ CBOS.pdf, retrieved 11.05.2011.

7. Konieczna J., Świądrowska E. Youth, Immigrants, Tolerance. Report from Field Studies in Schools. Warszawa; Towarzystwo Demokratyczne Wschód: 2008, p. 4.

8. Kułak A., Kułak P., Shpakou A., Okurowska-Zawada. Perception of Other Nations and Cultures by Polish Youth Studying Medical Sciences. Problems of Hygiene and Epidemiology 2011; 92(3): 679-687.

9. Kułak A., Okurowska-Zawada B., Kułak P. Perception of Other Nations and Cultures by Physical Therapy Stu- dents. Initial Report. In: Krajewska-Kułak E., Łukaszuk C.R., Lewko J. ed., On the Way to the Edge of Life, Vol. 8 Białystok; Uniwersytet Medyczny: 2011, pp. 207-224. 10. Krajewska-Kułak E., Shpakau A., Kułak W., Kułak A., Kułak P., Shpakou A., Okurowska-Zawada B. Tolerance of Polish and Belarus Youth Toward Other Nations and Minorities. In: Challenges of Modern Medicine, Białystok; 2012, pp. 345-346.

11. http://pbc.biaman.pl/Content/371/229729.pdf. J. Nikitorowicz: Borderland, Identity, Multicultural Education, Trans Humana, Wydawnictwo Uniwersyteckie Białystok 1995, retrieved 10.12.2013.

\section{Correspondence address:}

dr n. med. Katarzyna Van Damme-Ostapowicz Kierownik: prof. dr hab. med. Elżbieta Krajewska-Kułak Zakład Zintegrowanej Opieki Medycznej

Uniwersytet Medyczny w Białymstoku ul. M. Curie-Skłodowskiej 7a 15-096 Białystok, Poland Tel./fax +48 85/ 7485528 email: katarzyna.ostapowicz@gmail.com 